\title{
PERFORMANCE EVALUATION OF PRECISE POINT POSITIONING USING DUAL FREQUENCY MULTI-GNSS OBSERVATIONS
}

\author{
Jabir Shabbir MALIK \\ PhD Scholar, School of Aerospace Engineering, \\ Beijing Institute of Technology, Beijing, China \\ e-mail: jsmalik@bit.edu.cn
}

\begin{abstract}
In addition to GPS and GLONASS constellation, the number of (Global Navigation Satellite System) GNSS satellites are increasing, it is now possible to evaluate and analyze the position accuracy with multi GNSS constellation. In this paper, statistical assessment of static Precise Point Positioning (PPP) using GPS, GLONASS, dual system GPS/GLONASS, three system GPS/GLONASS/Galileo, GPS/GLONASS/BeiDou and multi system GPS/GLONASS/Galileo/BeiDou PPP combinations is evaluated. Observation data of seven whole days from seven IGS multi GNSS experiment (MGEX) stations is used for analysis. Position accuracy and convergence time is analyzed. Results show that the GPS/GLONASS positioning accuracy increases over GPS PPP. Standard deviations (STDs) of position errors for GPS PPP are 4.63, 3.00 and $6.96 \mathrm{~cm}$ in east, north and up components while STDs for GPS/GLONASS PPP are 4.10, 3.42 and $6.50 \mathrm{~cm}$ respectively. Root mean square for three dimension (RMS3D) for GPS/GLONASS PPP solution is $8.96 \mathrm{~cm}$. With the addition of Galileo and BeiDou to the combined GPS/GLONASS further enhances the positioning accuracy. Root mean square for horizontal component reach to $5.35 \mathrm{~cm}$ of GPS/GLONASS/Galileo/BeiDou PPP solutions. Results analysis of GPS/GLONASS/Galileo PPP solutions show an improvement of convergence time by only 3.81\% to achieve accuracy level of $3.0 \mathrm{~cm}$ over GPS/GLONASS/BeiDou PPP mode. Results also demonstrate that position accuracy improvement after adding BeiDou observations to the GPS/GLONASS PPP mode is not significant.
\end{abstract}

Keywords: MGEX, IGS, Open source package

\section{INTRODUCTION}

Precise Point Positioning (PPP) employs precise satellite orbit and clock products provided by the International GNSS Service (IGS) (Zumberge et al., 1997; Kouba, 2015). As, GNSS constellation is continuously developing and modernizing, next generation GPS III block system have successfully completed the in-orbit check after August 2019 (http://www.gps.gov). While, GLONASS system recently introduced the Code Division Multiple Access (CDMA) signals, while keeping the Frequency Division Multiple Access (FDMA) signals and the improvement of the on-board clock stability (http://www.glonass-iac.ru). At the end of 2020 or beginning of 2021, Galileo system will be upgraded the constellation from 24 to 26 operational satellites (also included In-Orbit Validation (IOV) three satellites). Old commercial service will be replaced by a High-Accuracy Service (HAS) and a Commercial Authentication Service 
(CAS). Currently, Galileo system is transmitting signals on five frequencies, that is, E1 (1575.42 MHz), E5a (1176.45 MHz), E5b (1207.14 MHz), E5 (1191.795 MHz) and E6 (1278.75 MHz) for several public services (Liu et al., 2019). Recently, 30 ${ }^{\text {th }}$ BeiDous-3 satellite were launched into geosynchronous orbit and currently BeiDous system comprises total of 55 satellites in orbit (www.en.beidou.gov.cn). BeiDous satellite based augmentation system (BDSBAS) provides services, among others, in aerospace, maritime affairs, transportation, and agriculture industry (Li et al., 2020). GNSS data has been widely used for applications such as positioning, navigation and timing (PNT), geodesy and geodynamics, Earth's atmosphere, GNSS-reflectometry and surface tomographic studies (Li et al., 2015a; Malik et al., 2018; Dong and Jin, 2018).

The performance of GPS and combined GPS/GLONASS PPP has been widely investigated, which confirms the improvements in accuracy and convergence time (Cai and Gao, 2007; Martin et al., 2011; Choy et al., 2013). Some work about the precision of the positioning results using online free Canadian Spatial Reference System PPP (CSRS-PPP) (https://webapp.geod.nrcan.gc.ca/geod/tools-outils/ppp.php) service and Magic-GNSS (developed by GMV company) (https://magicgnss.gmv.com/) PPP service has been reported (Martín et al., 2011). In their study, authors concluded that no significant improvement was observed between GPS and dual GPS/GLONASS PPP. In addition, mean time improvement between GPS and combined GPS/GLONASS PPP solutions is 3.1\%, $12.5 \%$ and $2.1 \%$ for the north component, east and up component, respectively. In Choy et al. (2013), conclusions were made that after 24 hours of static data observation, addition of GLONASS measurements with the GPS PPP, no apparent improvement was observed, while accuracy and precision of the GPS and combined GPS/GLONASS solutions were 2.0 and $1.0 \mathrm{~mm}$ in horizontal and vertical components, respectively. Single frequency (L1) and dual frequency (L1/L2) of GPS and GLONASS observations were post-processed with short time length using CSRS-PPP service in static platform (Dawidowicz and Krzan, 2014). Results indicated that dual frequency observations showed better PPP accuracy under limited satellite availability, though abruptly increasing the position dilution of precision (PDOP) values, decreased the PPP performance. Authors showed that after half an hour of observations, accuracies of $5.0 \mathrm{~cm}$ and $10.0 \mathrm{~cm}$ are achievable for horizontal and vertical component, respectively. (Yigit et al., 2014), postprocessed the GPS and GLONASS data for short $(1 \mathrm{~h})$ to long ( $24 \mathrm{~h})$ observations using Magic-GNSS service. Results indicated that with very short data observations, combined GPS/GLONASS PPP solutions provide better PPP estimates (23\% and 62\% of the $1 \mathrm{~h}$ data files) compared with the GPS only (17\%, 38\%) and GLONASS only (12\%, 31\%) PPP solutions. However, the difference of the combined GPS/GLONASS PPP solutions and GPS PPP solutions was not very large in three components (east, north, up) for 24 hour datasets. Experiment test was carried out for surveying applications in Turkey by post-processed dual frequency GPS and combined GPS/GLONASS observations using the CSRS-PPP and the Magic-GNSS service (Alkan et al., 2015). Authors concluded that the addition of GLONASS observations increase the number of satellite, but insignificant improvement of PPP positioning accuracy is achieved. In addition, the difference in horizontal component estimates from CSRSPPP service is $6 \mathrm{~cm}$ and $5 \mathrm{~cm}$ for GPS only and GPS/GLONASS combined results, respectively. For the height components, difference is $4 \mathrm{~cm}$ and $2 \mathrm{~cm}$ for GPS only and combined GPS/GLONASS solutions, while difference in horizontal and vertical component estimates from Magic-GNSS is larger. Rabbou and El-Rabbany (2015) performed a kinematic experiment for the comparison of their developed models, namely un-differenced ionosphere free and between satellite single differences (BSSD) ionosphere-free PPP model. Both un-differenced ionosphere free and between satellite single difference (BSSD) ionosphere-free PPP algorithms show decimeter-level positioning accuracy. However, the accuracy of BSSD ionosphere-free model is better than that of un-differenced model of GPS only PPP and GNSS PPP while no 
significant improvements for GLONASS-PPP. GPS and GLONASS dual frequency observations were post-processed in order to analyze and compare the position determination of the station coordinates and zenith tropospheric delay (ZTD) using four online PPP services, that is, Automatic Precise Point Service (APPS) developed by Jet Propulsion Laboratory (https://apps.gdgps.net/), GPS Analysis and Position Software (GAPS) developed by University of New Brunswick (http://gaps.gge.unb.ca/), CSRS-PPP and Magic-GNSS PPP (Guo, 2015). It was concluded that all the four web-based PPP services provide positioning accuracy up to 1.0 and less than $2.0 \mathrm{~cm}$. Abdallah et al., 2016, post processed GNSS data for short data spans to long data observations. Authors concluded that for $4 \mathrm{~h}$ and $8 \mathrm{~h}$ data observations, CSRS-PPP and APPS-PPP provides root mean square error three dimensional (RMSE3D) for equatorial and mid-latitudes stations, up to $2.0-3.0 \mathrm{~cm}$. They also found that the CSRS-PPP provides after $24 \mathrm{~h}$ for mid-latitude stations an RMSE3D of 4.4-4.6 $\mathrm{mm}$ and for the equatorial stations of 6.0-6.2 mm. While, APPS-PPP shows after $24 \mathrm{~h}$ for mid-latitude stations an RMSE3D of 3.8-6.7 $\mathrm{mm}$ and for the equatorial stations of $4.9-9.0 \mathrm{~mm}$.

Multi-constellation GNSS PPP, that is, GPS, GLONASS, Galileo and BeiDou integrated positioning has the potential to significantly improve the positioning accuracy due to the increased number of visible satellites and the improved satellite sky distribution (Lou et al., 2016; Cai et al., 2015). The triple combined PPP further increases the positioning accuracy and decreases the convergence time over the dual-constellation PPP (Cai et al., 2015). Multi GNSS (GPS/GLONASS/Galileo/BeiDou) PPP static solutions for 12 h datasets reach 0.17, 0.11 and $0.32 \mathrm{~m}$ in east, north and up directions, respectively (Li et al., 2015b). Moreover, real time multi-GNSS PPP can provide precise position estimates continuously about 99.5 \% even up to mask of $40^{\circ}$ elevation angle, for example, in urban canyons (Li et al., 2015c). (Kiliszek et al., 2020) showed that for the cut-off elevation angle of $40^{\circ}$, combined three system GPS/GLONASS/Galileo PPP enabled to achieve about 90\% availability of PPP solutions with accuracy level of $\mathrm{cm}$. The horizontal and vertical accuracy improvements of Galileo are observed as $8.0-11.0 \mathrm{~mm}$ and $23.0-30.0 \mathrm{~mm}$ for static and kinematic PPP, respectively. The results also showed that outliers can be reduced significantly by adding Galileo to the GPS/GLONASS combined PPP solutions for short observation (Ogutcu, 2020).

The main motivation of this study includes three aspects. Firstly, position accuracy achievable using GPS, GLONASS and combined GPS/GLONASS observations data post-processing. The second aspect is to investigate how positioning accuracy further improve with the addition of BeiDou and Galileo dual frequency observations using open source package PPPH. Lastly, this study also investigates signal residuals of different GNSS navigation satellite.

\section{MULTI-GNSS PPP OBSERVATIONS MODEL}

The basic observation equations for GNSS pseudorange $(P)$ and carrier phase $(\Phi)$ can be expressed as (Pan et al., 2017):

$$
\begin{aligned}
& P_{f, r}^{j}=\rho_{r}^{j}+c\left(\delta t_{r}^{j}-\delta T^{j}\right)+T_{r}^{j}+I_{f}^{j}+c\left(b_{f, r}-b_{f}^{j}\right)+\varepsilon\left(P_{f, r}^{j}\right) \\
& \Phi_{f, r}^{j}=\rho_{r}^{j}+c\left(\delta t_{r}^{j}-\delta T^{j}\right)+T_{r}^{j}-I_{f}^{j}+\lambda_{f}^{j}\left(N_{f}^{j}+B_{f, r}+B_{f}^{j}\right)+\xi\left(\Phi_{f, r}^{j}\right)
\end{aligned}
$$

where scripts $f, r$, and $j$ shows the frequency of GNSS satellite $(\mathrm{f}=1,2)$, ground receiver and GNSS satellite systems (G: GPS, R:GLONASS , E:Galileo, C:BeiDou), respectively; $\rho_{r}^{j}$ is the true geometric range between satellite and the receiver, $c$ is the speed of light in vacuum; $\delta \mathrm{t}_{r}^{j}$ and $\delta T^{j}$ are the receiver and satellite clock offset, respectively; $T_{r}^{j}$ is the tropospheric delay; $I_{f}^{j}$ is the first-order ionospheric delays; $b_{f, r}$ and $b_{f}^{j}$ are the frequency-dependent receiver and 
satellite hardware code biases respectively; $B_{f, r}$ and $B_{f}^{j}$ is the receiver and satellite carrier phase hardware biases respectively; $N_{f}^{j}$ is the non-integer carrier phase ambiguity term in cycle; $\lambda_{f}^{j}$ is the carrier wavelength of dual frequency in meters; $\varepsilon\left(P_{f, r}^{j}\right)$ and $\xi\left(\Phi_{f, r}^{j}\right)$ are unmodelled measurement errors (noise, multipath ) in GNSS code and phase observations respectively. The dual frequency ionosphere free linear combinations (IF) of multi GNSS pseudorange and phase observations can be formed as:

$$
\begin{aligned}
& P_{I F, r}^{j}=\rho_{r}^{j}+c\left(\widetilde{\delta t_{r}^{J}}-\widetilde{\delta T^{J}}\right)+T_{r}^{j}+\varepsilon\left(P_{I F, r}^{j}\right) \\
& \Phi_{I F, r}^{j}=\rho_{r}^{j}+c\left(\widetilde{\delta t_{r}^{J}}-\widetilde{\delta T^{J}}\right)+T_{r}^{j}+\lambda_{I F}^{j} \widetilde{B}_{I F}^{j}+\xi\left(\Phi_{I F, r}^{j}\right)
\end{aligned}
$$

where $\widetilde{\delta t_{r}^{J}}, \widetilde{\delta T^{\jmath}}$ and $\tilde{B}_{I F}^{j}$ are reformed receiver clock, satellite clock offset and ambiguity term, that is:

$$
\left\{\begin{array}{c}
\widetilde{c \delta t_{r}^{J}}=c\left(\delta t_{r}^{j}+b_{f, r}\right) \\
c \widetilde{\delta T^{J}}=c\left(\delta+b_{f, r}^{j}\right) \\
\tilde{B}_{I F}^{j}=\left(\beta_{I F, r}-\gamma_{I F}^{j}\right)+N_{I F}^{j}
\end{array}\right.
$$

where $\beta_{I F, r}$ and $\gamma_{I F}^{j}$ are the difference between hardware code and phase biases of receiver and satellite, respectively. Each GNSS system has separate clock offset parameter. Commonly, GPS time system is chosen as the reference time scale in combined multi GNSS PPP (GPS, GLONASS, Galileo and BeiDou). Therefore, multi GNSS IF PPP model can be written as follows:

$$
\begin{aligned}
& P_{I F, r}^{G}=\rho_{r}^{G}+c\left(\widetilde{\delta t}_{r}^{G}\right)+T_{r}^{G}+\varepsilon\left(P_{I F, r}^{G}\right) \\
& \Phi_{I F, r}^{G}=\rho_{r}^{G}+c\left(\widetilde{\delta t_{r}^{G}}\right)+T_{r}^{G}+\lambda_{I F}^{G} \tilde{B}_{I F}^{G}+\xi\left(\Phi_{I F, r}^{G}\right) \\
& P_{I F, r}^{R}=\rho_{r}^{R}+c\left(\widetilde{\delta t_{r}^{G}}+I S B_{r}^{R}\right)+T_{r}^{R}+\varepsilon\left(P_{I F, r}^{R}\right) \\
& \Phi_{I F, r}^{R}=\rho_{r}^{R}+c\left(\widetilde{\delta t}_{r}^{G}+I S B_{r}^{R}\right)+T_{r}^{R}+\lambda_{I F}^{R} \tilde{B}_{I F}^{R}+\xi\left(\Phi_{I F, r}^{R}\right) \\
& P_{I F, r}^{C}=\rho_{r}^{C}+c\left(\widetilde{\delta t}_{r}^{G}+I S B_{r}^{C}\right)+T_{r}^{C}+\varepsilon\left(P_{I F, r}^{C}\right) \\
& \Phi_{I F, r}^{C}=\rho_{r}^{C}+c\left(\widetilde{\delta t}_{r}^{G}+I S B_{r}^{C}\right)+T_{r}^{C}+\lambda_{I F}^{C} \tilde{B}_{I F}^{C}+\xi\left(\Phi_{I F, r}^{C}\right) \\
& P_{I F, r}^{E}=\rho_{r}^{E}+c\left(\widetilde{\delta t}_{r}^{G}+I S B_{r}^{E}\right)+T_{r}^{E}+\varepsilon\left(P_{I F, r}^{E}\right) \\
& \Phi_{I F, r}^{E}=\rho_{r}^{E}+c\left(\widetilde{\delta t_{r}^{G}}+I S B_{r}^{E}\right)+T_{r}^{E}+\lambda_{I F}^{E} \widetilde{B}_{I F}^{E}+\xi\left(\Phi_{I F, r}^{E}\right)
\end{aligned}
$$

where superscript $G, R, C$, and $E$ shows measurements from GPS, GLONASS, BeiDou and Galileo satellites respectively. Covariance matrix of measurement noise and process noise is established to get optimum PPP solution (Lou et al., 2016). Therefore, appropriate stochastic models are required in order to combine and estimate parameters of different GNSS measurements (Liu et al., 2017). A state vector which contains unknown parameters can be expressed as:

$$
\begin{gathered}
X=\left[\delta x, \delta y, \delta z, \widetilde{\delta t}_{r}^{G}, T_{z w d, r}, I S B_{r}^{R}, I S B_{r}^{C}, I S B_{r}^{E},\right. \\
\left.\widetilde{B}_{I F}^{G, 1}, \ldots, \widetilde{B}_{I F}^{G, k}, \widetilde{B}_{I F}^{R, 1}, \ldots, \widetilde{B}_{I F}^{R, k}, \widetilde{B}_{I F}^{C, 1}, \ldots, \widetilde{B}_{I F}^{C, k}, \tilde{B}_{I F}^{E, 1}, \ldots, \tilde{B}_{I F}^{E, k}\right]
\end{gathered}
$$

where $\delta x, \delta y$ and $\delta z$ are corrections in latitude, longitude and height components, respectively; $\widetilde{\delta t}_{r}^{G}$ is receiver clock offset; $T_{z w d, r}$ tropospheric zenith wet delay (ZWD); $I S B_{r}^{R}, I S B_{r}^{C}$ and $I S B_{r}^{E}$ are three internal system time difference biases for GLONASS, BeiDou and Galileo 
respectively with respect to GPS time system; $\tilde{B}_{I F}^{G}, \tilde{B}_{I F}^{R}, \tilde{B}_{I F}^{C}$ and $\tilde{B}_{I F}^{E}$ are float ambiguity parameter of GPS and GLONASS, Galileo and BeiDou observations, respectively. In multi GNSS PPP model, small weights assign to GLONASS code biases in order to reduce the effects of inter frequency biases (IFBs) for GLONASS satellite (Wanninger, 2012) (Liu et al., 2017).

\section{PERFORMANCE ANALYSIS AND STRATEGY}

Open software package, PPPH is adopted in this study, which is built and designed onto popular programming language MATLAB (Bahadur et al., 2018). Table 1 presents the basic features and capabilities of the open software package. Seven days of dataset is collected from 7 IGS stations (ftp://cddis.nasa.gov/gnss/data/daily/), which are distributed around the globe during January 7 to 13, 2018. IGS sites are also designated as MGEX stations, which are equipped with multi GNSS receivers that can simultaneously track and provide the dual frequency observations from GPS, GLONASS, Galileo and BeiDou satellites. Dual frequency observations for GPS L1 (1575.42 MHz), L2 (1227.60 MHz), for Galileo E1 (1575.42 MHz), E5a (1176.45 MHz), and for BeiDou B1 (1561.098 MHz), and B2 (1207.14 MHz) are employed.

Table 1. Basic software features of the open source

\begin{tabular}{|ll|}
\hline Source & http://newsys.ngs.noaa.gov/GPStoolbox/PPPH \\
\hline Software/version & MATLAB 2016b or later \\
\hline Estimator & Robust kalman filtering \\
\hline User mode & Static or Kinematic \\
\hline Phase ambiguities & Floating values and considered constant for each arc \\
\hline Constellation & GPS, GLONASS, Galileo and BeiDou system \\
\hline Observation & Ionosphere free (IF) linear combinations of dual frequency \\
\hline Weighting scheme & Equal weights, Elevation dependent; \\
\hline RINEX version/format & 3.0 mm carrier and 3.0 m code \\
\hline Precise orbits/clock & $3.03 / 3.02 / 2.11 / *^{*} \cdot *^{*}$, ${ }^{*}$. .rnx \\
\hline Ionospheric delay & IGS, MGEX \\
\hline Tropospheric delay model & Removed by using ionosphere free (IF) linear combination \\
\hline Dry component & Global Mapping Function (GMF) \\
\hline & Saastamoinen Model \\
Estimated Parameters & $\begin{array}{l}\text { Station Coordinates (X, Y, Z) in ECEF, } \\
\text { Receiver Clock offset, } \\
\text { zenith tropospheric delay, } \\
\text { east and north, gradients, } \\
\text { System Time Difference }\end{array}$ \\
\hline
\end{tabular}

All the 24 hour observations are sampled at 30 s interval. In combined multi GNSS PPP strategy, station coordinates are considered as time constant. Initial parameters for position (X, $\mathrm{Y}, \mathrm{Z}$ ), receiver clock offset and the tropospheric delay is set to $1 \times 10^{2} \mathrm{~m}, 1 \times 10^{5} \mathrm{~m}$, and $0.5 \times 10^{0}$ $\mathrm{m}$, respectively. spectrum densities for receiver clock offset, tropospheric wet component and inter system time difference are $10^{5} \mathrm{~m}^{2} / \mathrm{sec}, 10^{-9} \mathrm{~m}^{2} / \mathrm{sec}$ and $10^{-7} \mathrm{~m}^{2} / \mathrm{sec}$, respectively. International GNSS service Multi GNSS Experiment IGS MGEX precise satellite orbit and clock products are used in order to mitigate the orbit and clock errors (Montenbruck et al., 2017). Precise orbit and clock products provided by German Research Centre for Geosciences 
(GFZ) (ftp://cddis.nasa.gov/gnss/products/) with a sampling rate of $300 \mathrm{~s}$ and $30 \mathrm{~s}$ respectively are adopted for orbit and clock corrections (Bahadur et al., 2019).

Geographic location of IGS stations are shown in Figure 1.

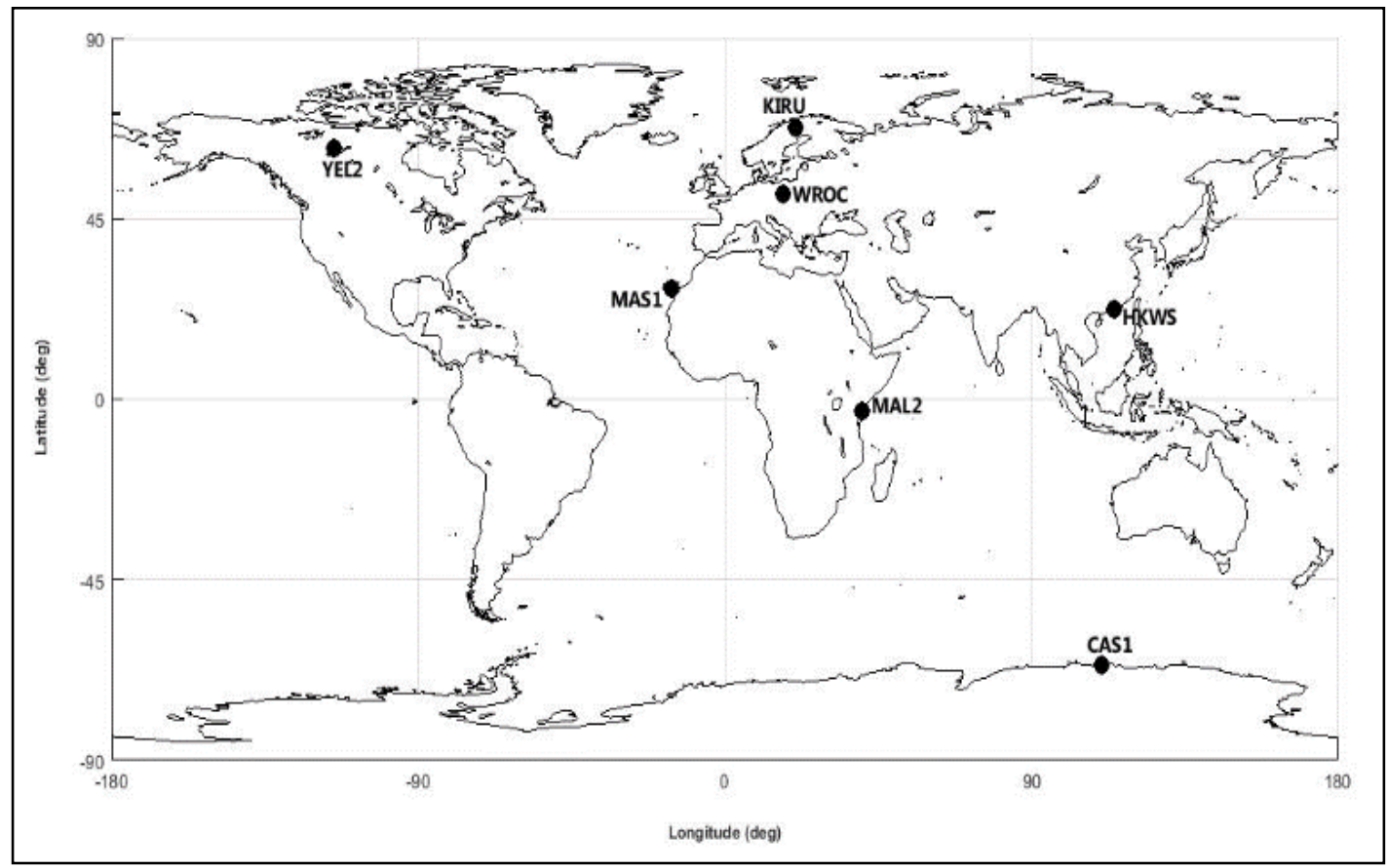

Figure 1. Geographical distribution of IGS stations used in this study

Table 2 shows the IGS study sites, coordinates, receiver type and antenna.

Table 2. Information about IGS MGEX stations coordinates, receiver and antenna

\begin{tabular}{|c|c|c|c|c|c|}
\hline \multirow{2}{*}{ Site } & \multirow{2}{*}{ Location } & \multicolumn{2}{|c|}{ Coordinates } & \multirow{2}{*}{ Receiver } & \multirow{2}{*}{ Antenna } \\
\cline { 3 - 4 } & & Latitude & Longitude & & \\
\hline HKWS & Hong Kong & $22^{\circ} 26^{\prime} 03.42^{\prime \prime}$ & $114^{\circ} 20^{\prime} 07.36^{\prime \prime}$ & LEICA GR50 & LEIAR25.R4 \\
\hline WROC & Poland & $51^{\circ} 06^{\prime} 47.75^{\prime \prime}$ & $17^{\circ} 03^{\prime} 43.30^{\prime \prime}$ & LEICA GR50 & LEIAR25.R4 \\
\hline MAL2 & Kenya & $-02^{\circ} 59^{\prime} 45.60^{\prime \prime}$ & $40^{\circ} 11^{\prime} 38.01^{\prime \prime}$ & SEPT POLARX4 & LEIAR25.R4 \\
\hline YEL2 & Canada & $62^{\circ} 28^{\prime} 52.76^{\prime \prime}$ & $-114^{\circ} 28^{\prime} 51.05^{\prime \prime}$ & SEPT POLARX5TR & LEIAR25.R4 \\
\hline KIRU & Sweden & $67^{\circ} 52^{\prime} 39.30^{\prime \prime}$ & $21^{\circ} 03^{\prime} 36.90^{\prime \prime}$ & SEPT POLARX4 & SEPCHOKE_MC \\
\hline MAS1 & Spain & $27^{\circ} 45^{\prime} 49.32^{\prime \prime}$ & $-15^{\circ} 37^{\prime} 59.88^{\prime \prime}$ & SEPT POLARX4 & LEIAR25.R4 \\
\hline CAS1 & Antartica & $-66^{\circ} 17^{\prime} 0.10^{\prime \prime}$ & $110^{\circ} 31^{\prime} 10.90^{\prime \prime}$ & TRIMBLE NETR9 & LEIAR25.R3 \\
\hline
\end{tabular}

Figure 2 shows mean number of available GNSS system and PDOP of six different GNSS PPP combinations (GPS-G, GLONASS-R GPS/GLONASS-GR, GPS/GLONASS/Galileo-GRE, GPS/GLONASS/BeiDou-GRC and GPS/GLONASS/Galileo/BeiDou-GREC). 

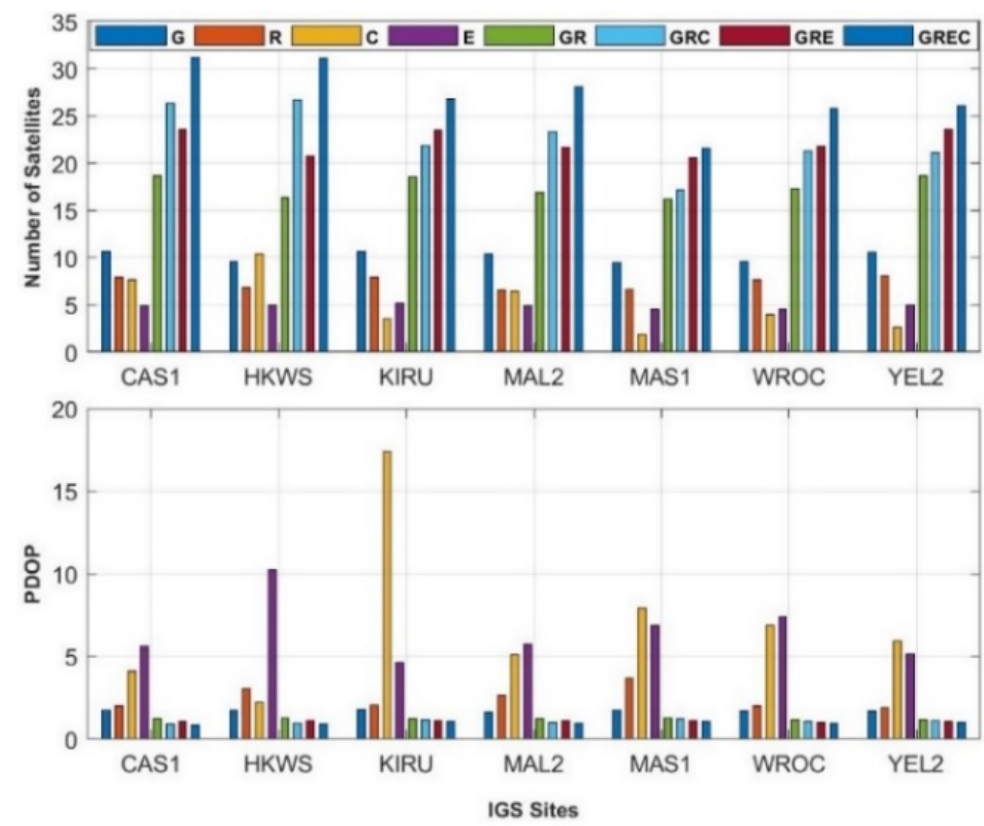

Figure 2. Mean number of available satellites and average PDOP values

Figure 3 outlines the availability of the average number of GNSS satellites and PDOP values of six GNSS PPP combinations.

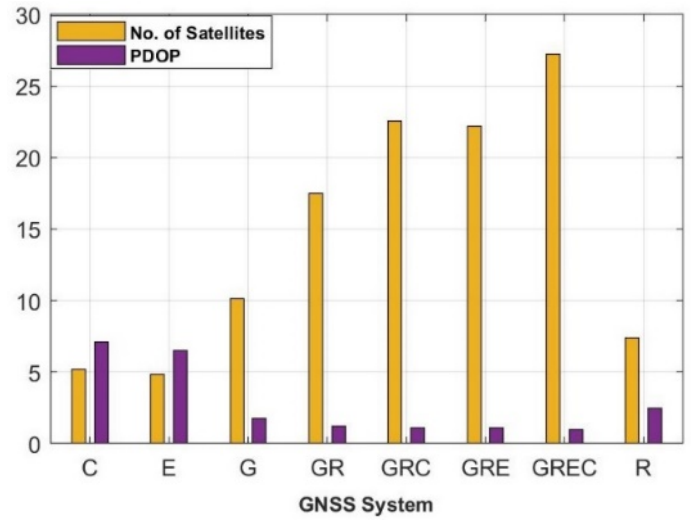

Figure 3. Average number of visible GNSS satellites and PDOP for different PPP mode

PDOP represent the quality of the satellite arrangements, geometric structure and satellite distribution (Pan et al., 2019). It can be seen from Figure 2 that higher number of GPS satellites are available followed by GLONASS constellation during datasets at all IGS stations. In addition, PDOP values of GPS are improved by $26.13 \%, 65.66 \%$ and $71.64 \%$ over GLONASS, BeiDou and Galileo PDOP, respectively. While, maximum number of BeiDous satellites are available at station HKWS. Moreover, maximum of 1.8 and 2.6 average number of BeiDou satellites are available at MAS1 and YELL2, respectively. On the other hand, minimum of 4 Galileo satellites are tracked at all IGS study sites. GPS PDOP values range within 1.67 to 1.83. With the addition of GLONASS to the GPS PPP further reduces the values of PDOP at the study sites. PDOP for combined GPS/GLONASS PPP reaches a maximum of 1.28 at HKWS station. It can be demonstrated from Figure 3 that with the integration of GLONASS and GPS system, the dual system has average 17.50 visible satellites and PDOP values show an improvement of 28.97\%, 47.91\% over GPS and GLONASS PPP mode. Moreover, combined three system GPS/GLONASS/Galileo and GPS/GLONASS/BeiDou PPP combinations have 22.20 and 22.50 number of available satellites, respectively. Furthermore, it can be illustrated 
from Figure 3 that multi GNSS PPP combinations enhanced the number of visible satellites and significantly reduce the PDOP compare with the single, dual and three GNSS system.

Table 3 shows the PPP processing strategy adopted for PPP solution. For the analysis of position accuracy, the dataset is processed in six different PPP combinations, that is, GPS, GLONASS, dual system GPS/GLONASS, triple system GPS/GLONASS/Galileo, GPS/GLONASS/BeiDou and multi GNSS (GPS/GLONASS/Galileo/BeiDou) PPP mode. Estimated coordinates are transformed from geocentric earth-centered earth-fixed (ECEF) coordinate system to topocentric east, north and up (E, N, U) system. The average position from the whole seven days with the 24 hours observation is adopted as the 'true' position. In order to evaluate the PPP performance, standard deviation (STD), root mean square (RMS) and convergence time is computed after 24 hours data processing. In this study, MATLAB version $2018 \mathrm{~b}$ is adopted for the performance analysis. For the analysis of convergence time, predefined threshold value is adopted in order to evaluate the convergence length. The solution is considered as converged if the 3D positioning error has been suppressed lower than the threshold value of $3.0 \mathrm{~cm}, 4.0 \mathrm{~cm}$ or $5.0 \mathrm{~cm}$ for at least twenty epochs. Moreover, typical three $(3.0-5.0 \mathrm{~cm})$ types of PPP threshold accuracy level is adopted only because some geodetic applications required within this accuracy.

Figure 3. PPP processing strategy adopted in the study

\begin{tabular}{|c|c|}
\hline GNSS system & GPS GLONASS, Galileo and BeiDou \\
\hline Platform & Static only \\
\hline Observables & Un-differenced, ionosphere free dual frequency observations \\
\hline Satellite orbit and clock & Final precise products of IGS MGEX Analysis center (GFZ) \\
\hline $\begin{array}{l}\text { Satellite antenna phase center } \\
\text { (PCOs/PCVs) }\end{array}$ & IGS antenna model IGS14_Antex \\
\hline $\begin{array}{l}\text { Receiver antenna phase center } \\
\text { (PCOs/PCVs) }\end{array}$ & $\begin{array}{l}\text { IGS antenna model IGS14_Antex, corrected by GPS and } \\
\text { GLONASS, GPS values for Galileo and BeiDou }\end{array}$ \\
\hline Differential Code Biases & CODE Analysis Center: P1-C1 \\
\hline Ionosphere delay & First order removed by IF linear dual frequency observations \\
\hline \multicolumn{2}{|l|}{ Troposphere } \\
\hline Dry component & Apriori values are used from Saastamoinen model \\
\hline Wet component & Estimated using the Global Mapping Function: GMF \\
\hline Estimator & Kalman Filter \\
\hline Elevation mask & $7^{\circ}$ \\
\hline Weighting method & Elevation dependent weights $\{1 / \sin$ (elevation) $\}$ \\
\hline Priori observation & Carrier phase: $0.003 \mathrm{~m}$ and code pseudoranges: $3 \mathrm{~m}$ at zenith \\
\hline Solid earth tide & Corrections applied \\
\hline Ocean Tide Loading & Corrections applied \\
\hline Phase Wind up & Corrections applied \\
\hline Relativistic effect & Corrections applied \\
\hline Output Analysis & $\begin{array}{l}\text { Position east, north, up, } \\
\text { Receiver clock bias, } \\
\text { 3D Positioning, convergence, } \\
\text { Tropospheric zenith total delay }\end{array}$ \\
\hline
\end{tabular}




\section{RESULTS ANALYSIS AND DISCUSSION}

\subsection{GPS, GLONASS and combined GPS/GLONASS performance assessment}

In this section, positioning accuracy of GPS, GLONASS and GPS/GLONASS combined PPP solution is investigated and analyzed. Statistical analysis is performed based on the performance metrics.

Figure 4 shows average STD in east, north and up direction for the GPS, GLONASS and combined GPS/GLONASS PPP solutions at the IGS sites. Table 4 provides the statistical summary of positioning errors for GPS, GLONASS and combined GPS/GLONASS PPP mode.
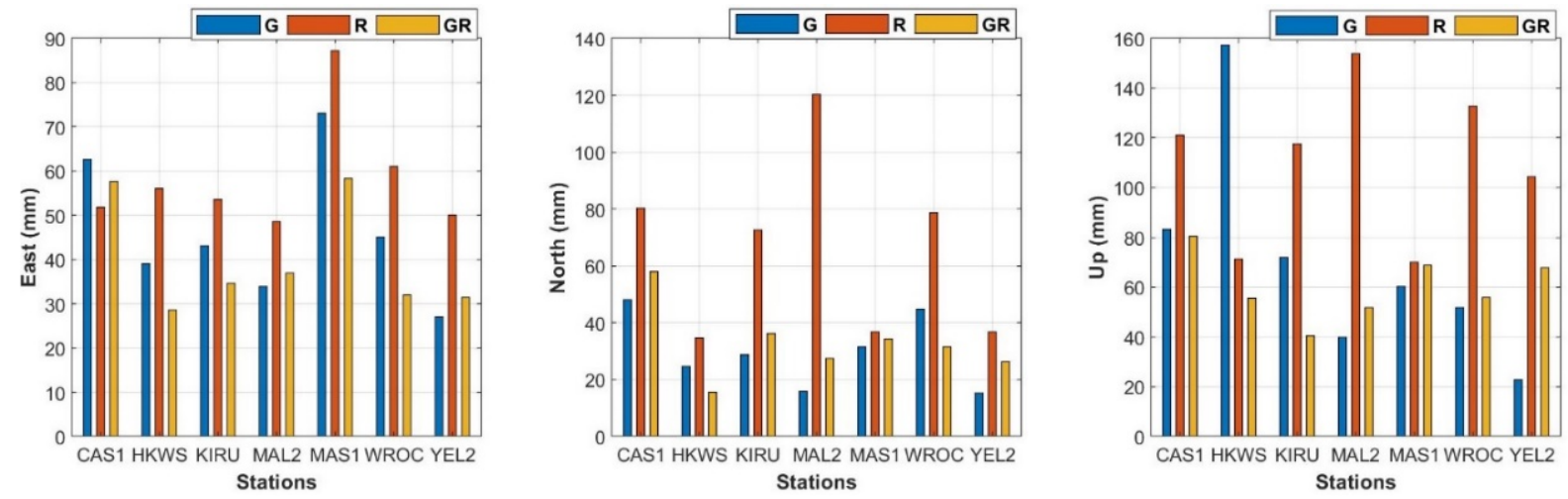

Figure 4. Bar diagram of average standard deviation in east, north, up direction for GPS, GLONASS and combined GPS/GLONASS PPP mode

Table 4. Positioning error of the GPS, GLONASS and combined GPS/GLONASS PPP solutions (unit: $\mathrm{cm}$ )

\begin{tabular}{|c|c|c|c|}
\hline System & East & North & Up \\
\hline GPS & 4.63 & 3.00 & 6.96 \\
\hline GLONASS & 5.54 & 6.57 & 11.01 \\
\hline GPS/GLONASS & 4.10 & 3.42 & 6.50 \\
\hline
\end{tabular}

As we can see from Figure 4 that positioning accuracy is enhanced for the combined GPS/GLONASS PPP in east and up direction than GPS PPP solutions. GPS/GLONASS PPP solutions give 5.0-10.0 mm smaller STD values as compared to the GPS PPP. While, some discrepancies are observed in north direction for the GPS/GLONASS solutions On the other hand, GLONASS PPP solutions are worse. Results given in Table 4 show that GPS PPP reach $4.63 \mathrm{~cm}, 3.00$ and $6.96 \mathrm{~cm}$ in east, north and up components, respectively. Moreover, GPS PPP solutions show an improvement of $38.46 \%, 56.85 \%$ and $34.28 \%$ over GLONASS PPP mode. In addition, GLONASS PPP solutions are worse than the GPS PPP with a factor of 1.25, 1.50 and 2.0 in east, north and up components, respectively. Furthermore, with the addition of GLONASS measurements to the GPS solutions show an improvement of $6.39 \%$ and $46.36 \%$ in east component over GPS and GLONASS PPP solutions, respectively. However, combined GPS/GLONASS PPP results do not show significant improvement in up direction over GPS PPP. STD of combined GPS/GLONASS positioning errors are reduced and reach $6.50 \mathrm{~cm}$. In addition, with the exception of YEL2 site, PPP solutions for combined GPS/GLONASS are improved by $16.34 \%$ particularly in up component over GPS PPP. This is because up component for GPS PPP reaches 157 mm at HKWS, as presented in Figure 4. 
Figure 5 shows RMS 3D for three different PPP combinations. Root mean square error for three dimension (3D) in east, north and up component is calculated as follows:

$$
R M S E_{3 D}=\sqrt{R M S E_{E}^{2}+R M S E_{N}^{2}+R M S E_{U}^{2}}
$$

where $\mathrm{RMSE}_{\mathrm{E}}, \mathrm{RMSE}_{\mathrm{N}}$ and $\mathrm{RMSE}_{\mathrm{U}}$ are the root mean square errors in east, north and up, respectively. RMS for GPS PPP solution is improved by $51.50 \%$ and $37.98 \%$ in horizontal and 3D component over GLONASS PPP, respectively. Table 5 gives the 3D and 2D positioning errors for GPS, GLONASS and combined GPS/GLONASS PPP mode. Herein, 2D and 3D refers to horizontal and spatial positioning, respectively.

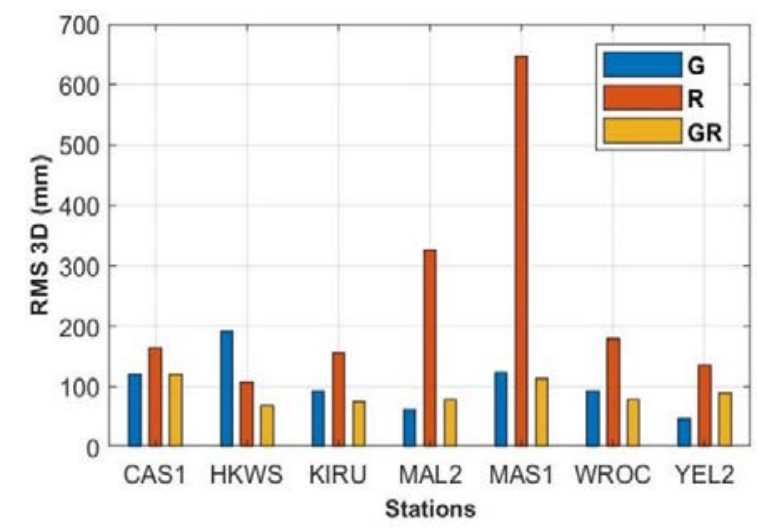

Figure 5. Average RMS 3D positioning errors of three PPP mode

Table 5. Comparison of positioning error of the GPS, GLONASS and combined GPS/GLONASS PPP solutions (unit: $\mathrm{cm}$ )

\begin{tabular}{|c|c|c|c|c|}
\hline \multirow{2}{*}{ System } & \multicolumn{4}{|c|}{ Positioning } \\
\cline { 2 - 5 } & \multicolumn{2}{|c|}{ 2D } & \multicolumn{2}{c|}{ 3D } \\
\cline { 2 - 5 } & Mean & RMS & Mean & RMS \\
\hline GPS & 2.21 & 5.91 & 4.67 & 10.45 \\
\hline GLONASS & 5.90 & 11.39 & 8.04 & 16.53 \\
\hline GPS/GLONASS & 2.11 & 5.87 & 3.28 & 8.96 \\
\hline
\end{tabular}

It can be inferred from Figure 5 that 3D position accuracy is enhanced with the addition of GLONASS observations to the GPS PPP. However, combined GPS/GLONASS PPP show insignificant improvement in 3D component at stations CAS1, MAL2 and YEL2. The reason is due to the average spatial geometry and the number of GPS satellites available for observations are good and sufficient to provide better PPP estimates at both the stations. Results given in Table 5 conclude that RMS 3D positioning errors are decreased with the addition of GLONASS observations. Furthermore, RMS3D for GPS/GLONASS PPP solution is $8.96 \mathrm{~cm}$, thus RMS is decreased by $2.0 \mathrm{~mm}$ and $15.0 \mathrm{~mm}$ as compared with GPS alone PPP solutions in horizontal and 3D component, respectively.

Table 6 presents the maximum, minimum and mean errors in east, north and up components for GPS, GLONASS and combined GPS/GLONASS PPP solutions. From the results given in Table 6, it can be demonstrated that the average difference of maximum errors between GPS and GPS/GLONASS PPP is $0.30 \mathrm{~m}$ and $0.80 \mathrm{~m}$ in east and north, component respectively. Figure 6 gives the convergent session's length for GPS, GLONASS and combined 
GPS/GLONASS PPP mode for 3D accuracy level of 3.0, 4.0 and $5.0 \mathrm{~cm}$. In Figure 6, letter A, $\mathrm{B}$ and $\mathrm{C}$ represents position converges at 3.0, 4.0 and $5.0 \mathrm{~cm}$ accuracy, respectively.

Table 6. Maximum, Minimum and Mean errors of the GPS, GLONASS and combined GPS/GLONASS PPP solutions (unit: $\mathrm{m}$ )

\begin{tabular}{|c|c|c|c|c|c|c|c|c|c|}
\hline \multirow{2}{*}{ System } & \multicolumn{3}{|c|}{ East } & \multicolumn{3}{c|}{ North } & \multicolumn{3}{c|}{ Up } \\
\cline { 2 - 11 } & Max. & Min. & Mean & Max. & Min. & Mean & Max. & Min. & Mean \\
\hline GPS & 1.59 & -2.22 & 0.30 & 2.25 & -1.61 & 0.13 & 4.59 & -4.14 & 0.01 \\
\hline GLONASS & 2.73 & -5.44 & 0.29 & 4.51 & -3.74 & 0.14 & 7.26 & -8.20 & -0.01 \\
\hline GPS/GLONASS & 1.91 & -2.66 & 0.31 & 3.12 & -1.90 & 0.13 & 4.33 & -3.97 & -0.01 \\
\hline
\end{tabular}
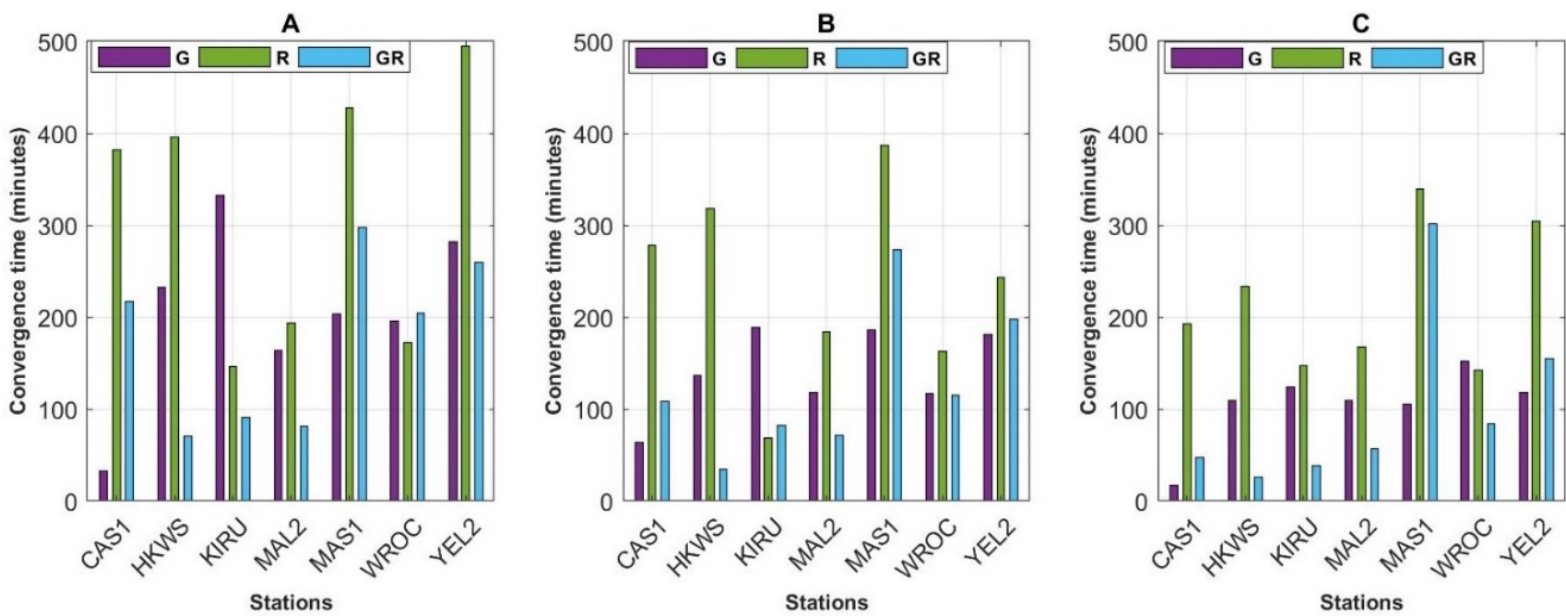

Figure 6. Average convergence time for GPS, GLONASS and combined GPS/GLONSS PPP mode

Analysis of Figure 6 illustrates that inclusion of GLONASS observations to the GPS PPP accelerates the convergence speed and significantly decrease the convergence time length. However, average convergence time for combined GPS/GLONASS PPP at stations CAS1 and MAS1 increased to achieve 3D accuracy level of 3.0, 4.0 and $5.0 \mathrm{~cm}$. This may be related that with the addition of GLONASS observations also increases the number of parameters to be estimated, that is, epoch-independent carrier phase ambiguity. GPS PPP solutions show a significant improvement of convergence time period to achieve accuracy level of 3.0, 4.0 and $5.0 \mathrm{~cm}$ comparing with the GLONASS convergent sessions. While, at station WROC GLONASS, only PPP shows very fast convergence speed and takes 146.5 min to converge accuracy level of $3.0 \mathrm{~cm}$ than the GPS only counterpart. On the contrary, at station CAS1 GPS, PPP takes only 32.14 min to achieve an accuracy level of $3.0 \mathrm{~cm}$

Table 7 outlines the average convergence time for the GPS, GLONASS and GPS/GLONASS PPP solutions. Results given in Table 7 show that GPS PPP takes 206.15 min to converge 3.0 $\mathrm{cm}$. In addition, average convergence time for GPS PPP is reduced by $14.69 \%$ over GLONASS PPP solutions. Adding the GLONASS observations reduce the average convergence time by $6.66 \%$ to converge accuracy level of better than $4.0 \mathrm{~cm}$. However, the combined GPS/GLONASS PPP reduces the average convergence time and takes $174.39 \mathrm{~min}$ to achieve $3.0 \mathrm{~cm}$ accuracy but shows insignificant improvement over GPS convergence time. 
Table 7. Average convergence time for GPS, GLONASS and combined GPS/GLONASS PPP mode (unit: $\min$ )

\begin{tabular}{|c|c|c|c|c|c|c|}
\hline \multirow{2}{*}{ System } & \multicolumn{3}{|c|}{ Accuracy } & \multicolumn{3}{c|}{ STD } \\
\cline { 2 - 7 } & $\mathbf{3 . 0} \mathbf{~ c m}$ & $\mathbf{4 . 0} \mathbf{~ c m}$ & $\mathbf{5 . 0} \mathbf{~ c m}$ & $\mathbf{3 . 0} \mathbf{~ c m}$ & $\mathbf{4 . 0} \mathbf{~ c m}$ & $\mathbf{5 . 0} \mathbf{~ c m}$ \\
\hline GPS & 206.15 & 141.54 & 104.74 & 26.7 & 21.4 & 17.6 \\
\hline GLONASS & 316.13 & 234.64 & 217.94 & 32.4 & 29.3 & 24.7 \\
\hline GPS/GLONASS & 174.39 & 125.85 & 101.05 & 24.5 & 22.6 & 15.8 \\
\hline
\end{tabular}

\subsection{Assessment of GPS/GLONASS/Galileo, GPS/GLONASS/Beidou and multi GNSS PPP performance}

In this section, performance assessment of GPS/GLONASS/Galileo, GPS/GLONASS/BeiDou and multi GNSS PPP combination is investigated.

Figure 7 presents the average STD values in east, north, up component for three different PPP combinations.
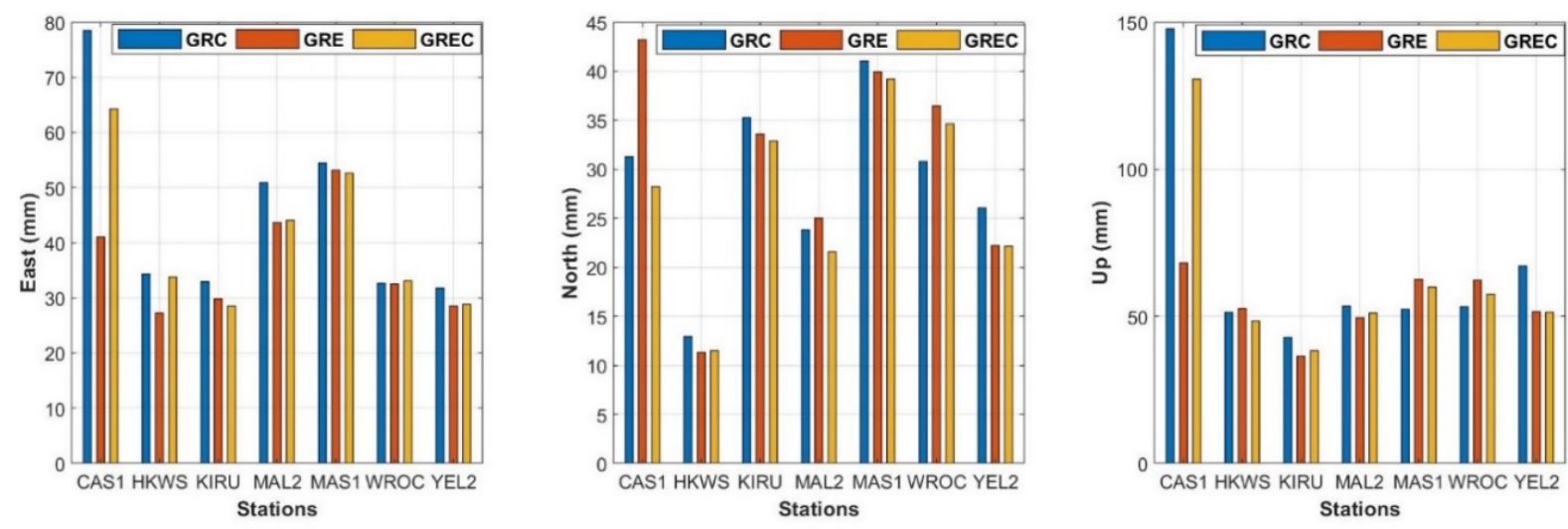

Figure 7. Bar diagram of average standard deviation in east, north, up direction for GPS/GLONSS/Galileo, GPS/GLONSS/BeiDou and multi GNSS PPP combinations

Analysis of Figure 7 confirms that with the addition of Galileo to the GPS/GLONASS generally produces smaller STD values for east, north and up coordinate components than the GPS/GLONASS/BeiDou PPP solutions. From Figure 7, it appears that CAS1 station exhibits larger differences of the STDs between the combined GPS/GLONASS/Galileo and GPS/GLONASS/BeiDou PPP solutions and reach 45.0, 12.0 and $91.0 \mathrm{~mm}$ for the east, north, and up components respectively. While for the other IGS stations, average differences of STD values (east, north, up) between the GPS/GLONASS/Galileo and GPS/GLONASS/BeiDou solutions are 4.0, 1.50 and $2.0 \mathrm{~mm}$, respectively. Multi-GNSS positioning accuracy is enhanced by 10.0-15.0 mm and 5.0-6.0 mm in north and up component at CAS1 and HKWS and WROC, respectively. In addition, on average, PPP solutions for multi GNSS are marginally improved by $1.0-2.0 \mathrm{~mm}$.

Table 8 outlines the statistical summary of positioning errors for the three different PPP combinations mode. 
Table 8. Comparison of positioning error of the GPS/GLONASS/Galileo, GPS/GLONASS/BeiDou and multi GNSS PPP mode (unit: $\mathrm{cm}$ )

\begin{tabular}{|c|c|c|c|}
\hline System & East & North & Up \\
\hline GRC & 4.51 & 2.87 & 6.69 \\
\hline GRE & 3.66 & 3.02 & 5.47 \\
\hline GREC & 4.07 & 2.72 & 6.10 \\
\hline
\end{tabular}

Table 9 provides RMS 2D and 3D positioning errors for GPS/GLONASS/Galileo, GPS/GLONASS/BeiDou and multi GNSS PPP mode.

Table 9. Positioning error of the GPS/GLONASS/Galileo, GPS/GLONASS/BeiDou and multi GNSS PPP solutions. (Unit: $\mathrm{cm}$ )

\begin{tabular}{|c|c|c|c|c|}
\hline \multirow{2}{*}{ System } & \multicolumn{4}{|c|}{ Positioning } \\
\cline { 2 - 5 } & \multicolumn{2}{|c|}{ 2D } & \multicolumn{2}{c|}{ 3D } \\
\cline { 2 - 5 } & Mean & RMS & Mean & RMS \\
\hline GRC & 2.03 & 5.85 & 3.15 & 9.62 \\
\hline GRE & 1.98 & 5.21 & 3.08 & 8.09 \\
\hline GREC & 1.93 & 5.35 & 2.97 & 8.75 \\
\hline
\end{tabular}

Results given in Table 9 confirms that RMS 2D and 3D component for GPS/GLONASS/Galileo is improved by $10.78 \%, 10.88 \%$ and $2.70 \%, 3.52 \%$ over GPS/GLONASS/BeiDou and multi GNSS PPP results, respectively. Moreover, results given in Table 9 show that PPP solutions after adding BeiDou observations to the GPS/GLONASS PPP mode is not significant due to, firstly, the BeiDou satellite orbits and clock corrections have relative low quality, specifically for GEO satellites (Guo et al., 2017); and secondly, antenna phase corrections for the BeiDou satellites. Moreover, the negative contribution of BeiDou satellites could be possibly caused by the multipath or systematic errors that may not optimally handled when combined with GPS/GLONASS observations (Zhao et al., 2015).

Figure 8 presents bar diagram of RMS for 3D positioning errors of three different PPP combinations. It can be inferred from Figure 8 that mean difference of RMS 3D between PPP solutions for the GPS/GLONASS/Galileo and GPS/GLONASS/BeiDou PPP is only $10.0 \mathrm{~mm}$. Furthermore, practically same values were obtained for GRE and multi GNSS PPP combinations.

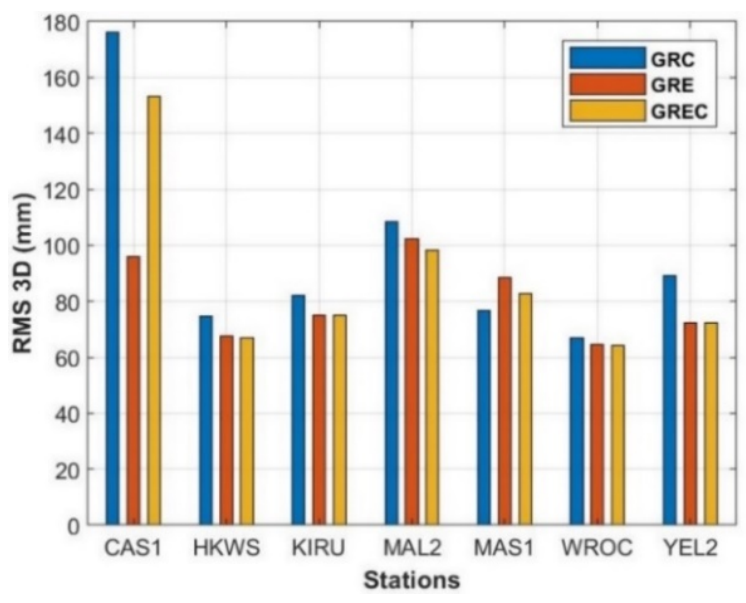

Figure 8. Average 3D RMS positioning errors of GRE and GRC and multi GNSS PPP solutions 
Table 10 presents the maximum, minimum and mean errors of GPS/GLONASS/Galileo, GPS/GLONASS/BeiDou and multi GNSS PPP solutions calculated from all IGS stations. Results from Table 10 indicate that the combined GPS/GLONASS/Galileo/BeiDou PPP solutions have the smallest maximum amount of errors in east and north component in comparison with GPS/GLONASS/Galileo PPP. However, maximum errors for G/R/E PPP in up component are smaller in comparison with GPS/GLONASS/BeiDou and multi GNSS PPP solutions. On the other hand, maximum errors in east and up components for GPS/GLONASS/BeiDou PPP mode have larger difference than GPS/GLONASS/Galileo and multi GNSS PPP.

Table 10. Positioning errors maximum, minimum and mean of the GPS/GLONASS/Galileo, GPS/GLONASS/BeiDou and multi GNSS PPP solutions (unit: m)

\begin{tabular}{|c|c|c|c|c|c|c|c|c|c|}
\hline \multirow{2}{*}{ System } & \multicolumn{3}{|c|}{ East } & \multicolumn{3}{c|}{ North } & \multicolumn{3}{c|}{ Up } \\
\cline { 2 - 11 } & Max. & Min. & Mean & Max. & Min. & Mean & Max. & Min. & Mean \\
\hline GRC & 1.73 & -2.92 & 0.30 & 1.71 & -1.91 & 0.14 & 5.29 & -2.61 & -0.10 \\
\hline GRE & 1.70 & -2.08 & 0.31 & 2.21 & -1.43 & 0.13 & 4.13 & -3.34 & -0.01 \\
\hline GREC & 1.54 & -2.45 & 0.31 & 1.57 & -1.61 & 0.13 & 5.08 & -2.47 & -0.01 \\
\hline
\end{tabular}

Figure 9 presents the convergent session's length for GPS/GLONASS/Galileo, GPS/GLONASS/BeiDou and multi GNSS PPP mode for 3D accuracy level of 3.0, 4.0 and 5.0 $\mathrm{cm}$. In Figure 9, letter A, B and C represents position accuracy converges at 3.0, 4.0 and 5.0 $\mathrm{cm}$, respectively. Table 11 shows the average convergence time of 3D accuracy for $3.0 \mathrm{~cm}, 4.0$ $\mathrm{cm}$ and $5.0 \mathrm{~cm}$ from all stations for three different PPP combinations presented in Figure 9.
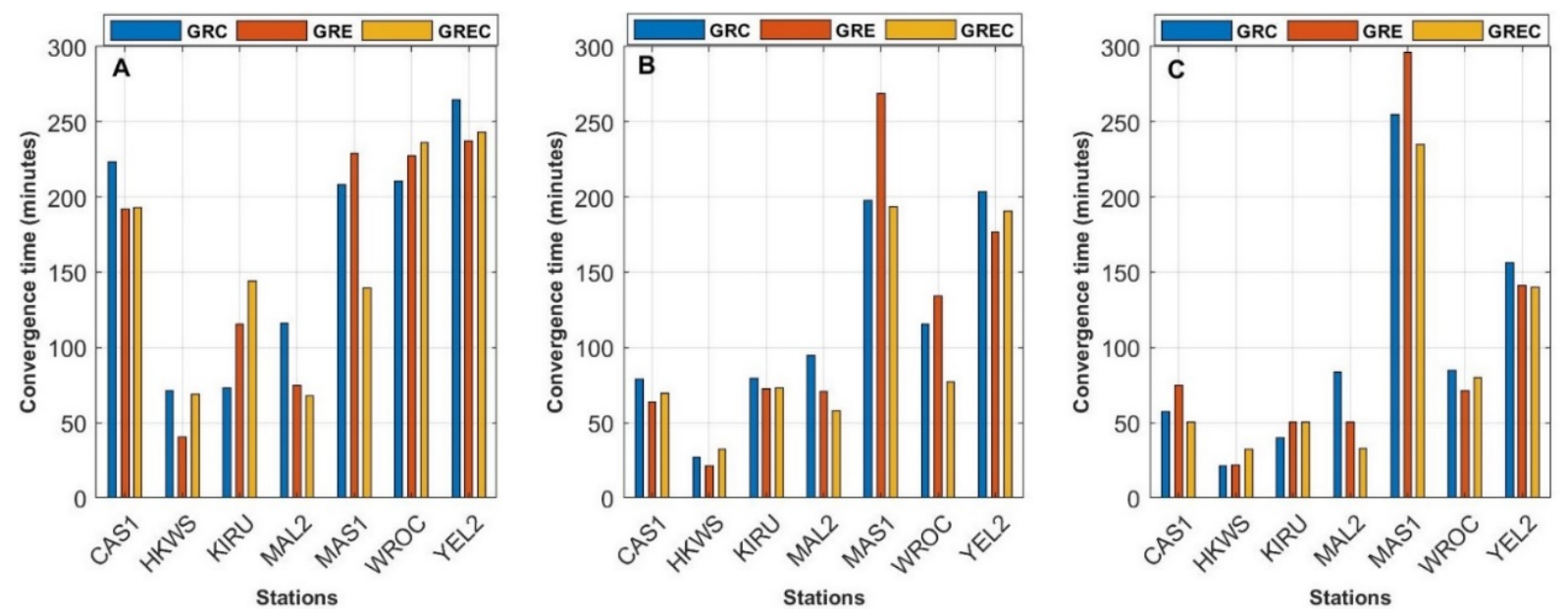

Figure 9. Average convergence time for three different GNSS PPP combinations

Table 11. Mean convergence time for three system (GRC, GRE) and multi GNSS system (GREC) PPP mode (Unit: min)

\begin{tabular}{|c|c|c|c|c|c|c|}
\hline \multirow{2}{*}{ System } & \multicolumn{3}{|c|}{ Accuracy } & \multicolumn{3}{c|}{ STD } \\
\cline { 2 - 7 } & $\mathbf{3 . 0} \mathbf{~ c m}$ & $\mathbf{4 . 0} \mathbf{~ c m}$ & $\mathbf{5 . 0} \mathbf{~ c m}$ & $\mathbf{3 . 0} \mathbf{~ c m}$ & $\mathbf{4 . 0} \mathbf{~ c m}$ & $\mathbf{5 . 0} \mathbf{~ c m}$ \\
\hline GRC & 166.77 & 114.00 & 99.76 & 23.2 & 18.8 & 12.0 \\
\hline GRE & 159.57 & 115.38 & 100.87 & 21.4 & 16.1 & 11.8 \\
\hline GREC & 156.15 & 99.24 & 88.80 & 20.8 & 11.4 & 9.9 \\
\hline
\end{tabular}


It can be illustrated in Figure 9 and results shown in Table 11 that the multi GNSS PPP mode accelerates the convergence speed and significantly decrease the convergence time length to achieve the desired positioning accuracy. However, GPS/GLONASS/Galileo PPP solutions show an improvement of convergence time by 3.81\% to achieve an accuracy level of $3.0 \mathrm{~cm}$ over GPS/GLONASS/BeiDou PPP mode. It can be demonstrated from the average convergence time given in Table 11 that multi GNSS PPP solutions take 99.24 min to converge to accuracy level of $4.0 \mathrm{~cm}$. In addition, multi GNSS PPP reduced the convergence time by $11.69 \%$ and 2.26\% over GPS/GLONASS/BeiDou and GPS/GLONASS/Galileo PPP solutions for accuracy level of $3.0 \mathrm{~cm}$. On the other hand, to achieve the accuracy level of better than 4.0 and $5.0 \mathrm{~cm}$, combined GPS/GLONASS/BeiDou PPP takes 114.0 and 99.76 min, respectively. Furthermore, PPP solutions show fastest convergence at accuracy level of $4.0 \mathrm{~cm}$ but do not show any improvement over GPS/GLONASS/Galileo PPP solutions.

\subsection{Analysis of GNSS system residuals}

In GNSS PPP technique, the observation residuals contain the multipath errors, orbit and clock errors, measurement noise and other un-modeled errors. In addition, residuals can be used as an important index for the assessment of the observation quality, positioning accuracy and parameterization in Kalman filter. Figure 10 and Figure 11 shows the IF phase and code observation residuals of the multi GNSS at MAL2 on day of the year (DOY) 007, respectively. Different colors show the different satellites of GPS, GLONASS, Galileo and BeiDou system. It can be seen from Figures 10 and 11 that some large discrete code and phase residuals are noticeable. It can be illustrated from Figure 10 that the RMS of the phase residuals of GPS, GLONASS, Galieo and BeiDou is 2.68, 2.01, 1.55 and $1.62 \mathrm{~mm}$, respectively. Analysis of Figure 11 demonstrates that RMS value of GPS code residuals is high, about $0.92 \mathrm{~m}$. Moreover, code observation for Galileo is lower than GPS, GLONASS and BeiDou code observations; this is may be attributed to the signal quality of the Galileo E1/E5a dual frequency observations is better than GPS, GLONASS and BeiDou signals (Xia et al., 2019).
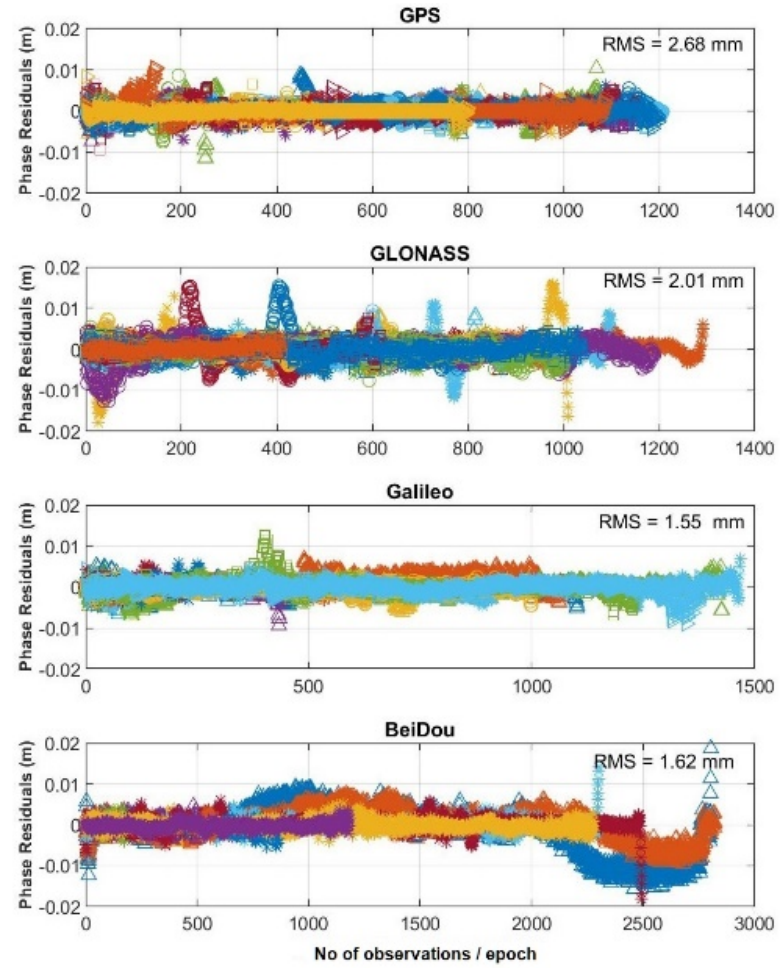

Figure 10. Phase residuals of IF combination obtained by GPS/GLONASS/Galileo/BeiDou PPP solutions at MAL2 on DOY 007 

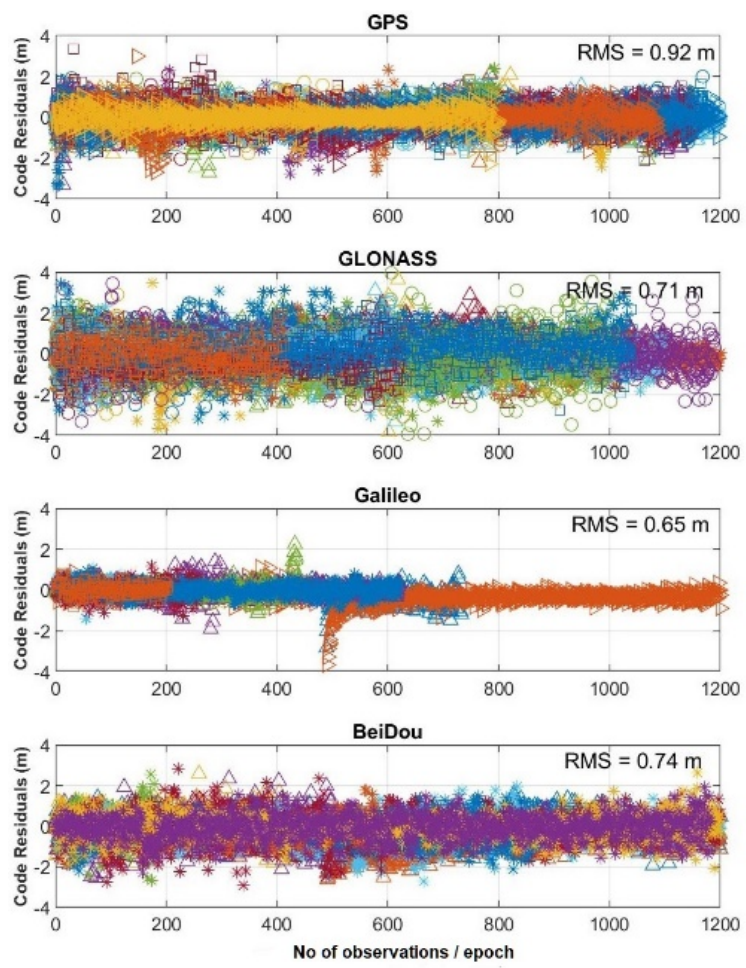

Figure 11. Code residuals of IF combination obtained by GPS/GLONASS/Galileo/BeiDou PPP solutions at MAL2 on DOY 007

Orbital type of the different GNSS satellite system is also analyze in order to assess and investigate the PPP performance of the single and multi GNSS PPP. Figure 12 depicts the code observations residual for different GNSS orbital type observed at CAS1 on DOY 007. It can be illustrated from Figure 12 that different orbital types show different variation characteristics.

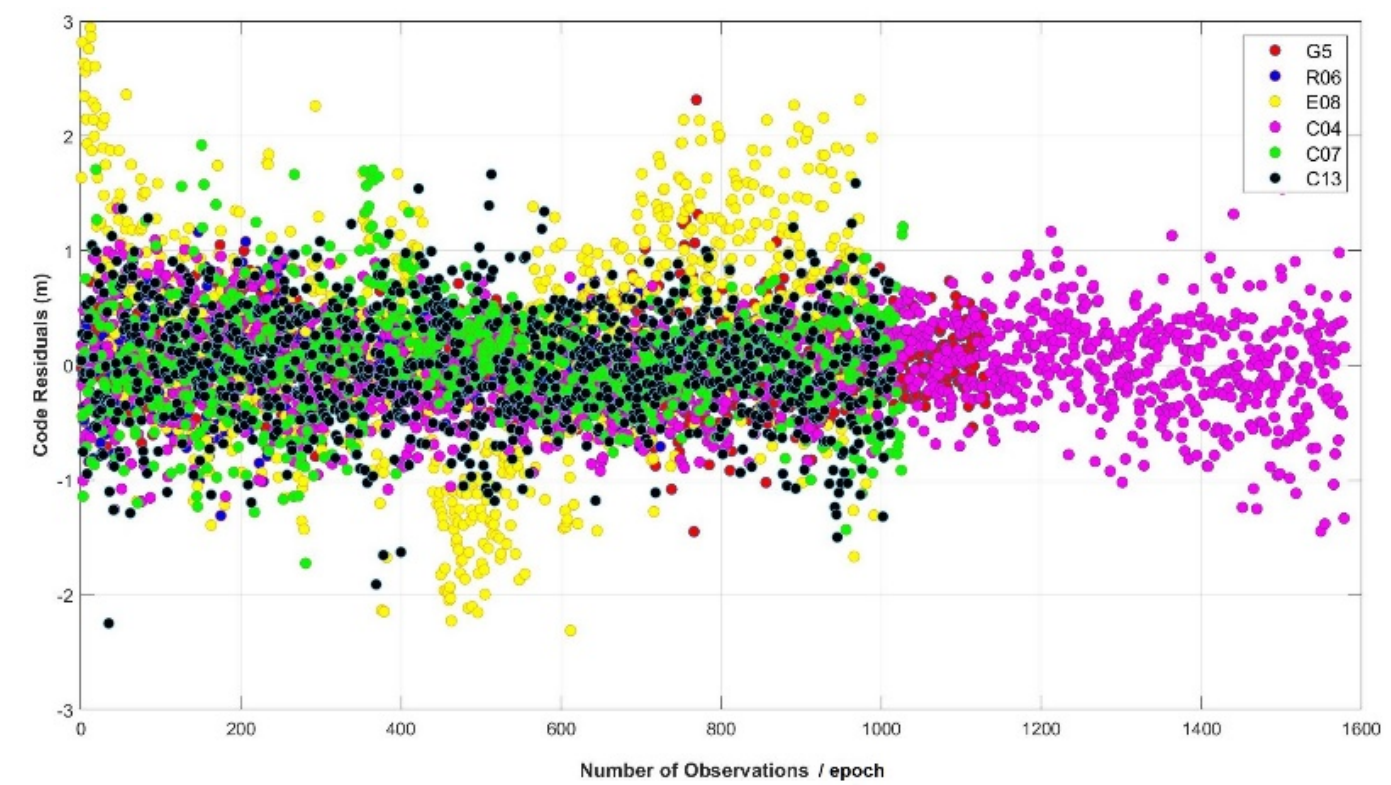

Figure 12. Code observation residuals of typical GNSS satellite orbital types (GPS G5, GLONASSR06, Galileo-E08, BeiDou-C04 (GEO), BeiDou-C07 (IGSO) and BeiDou-C13 (MEO)) at CAS1 on DOY 007 for 24 hour duration

Figure 13 presents the RMS values of code and phase observations with STD of error bar lines for the GNSS satellite orbital type of one week of data from all IGS stations. Code and phase 
observation residuals for BeiDou constellation has different RMS values. Analysis of Figure 13 demonstrates that RMS of GPS code residual is $1.7 \mathrm{~m}$, while GLONASS code residual is $2.0 \mathrm{~m}$. On the other hand, Galileo code residuals are $1.5 \mathrm{~m}$ and for BeiDou GEO satellites is smallest and about $1.1 \mathrm{~m}$, while RMS of BeiDou MEO and IGSO is $2.2 \mathrm{~m}$ and $1.78 \mathrm{~m}$, respectively. STD error bars of code residuals for GPS, GLONASS and Galileo system is 0.6, 0.8 and $0.4 \mathrm{~cm}$, respectively. While, error bar for Beidous MEO, IGSO and GEO satellites reach 0.9, 0.6 and $0.3 \mathrm{~cm}$, respectively. It can be illustrated from Figure 13 that BeiDou GEO satellite has the smallest STD values of phase residuals and reach $10 \mathrm{~mm}$ in comparison with BeiDou MEO and IGSO satellite with error reaches 17 and $14 \mathrm{~mm}$, respectively. Moreover, phase residuals for the Galileo is large and reach 25 mm (Li et al., 2015; Xia et al., 2019).
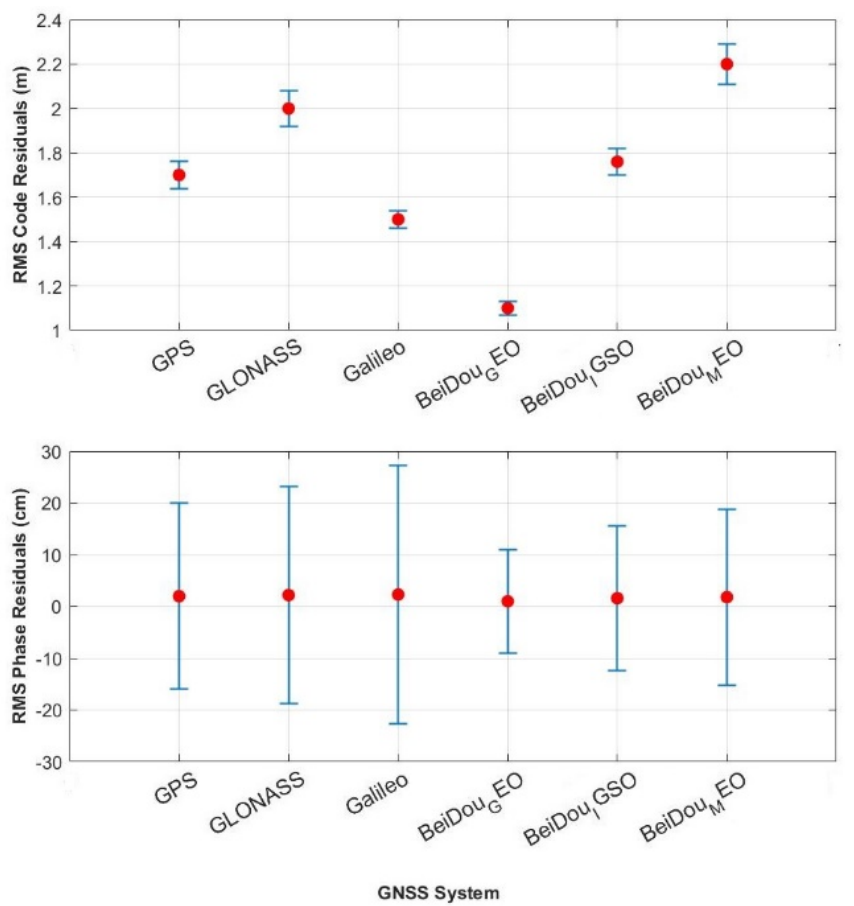

Figure 13. Bar diagram of RMS values of code and phase observation residuals with error bars for different GNSS system

\section{CONCLUSION}

With the inclusion of satellites from other GNSS constellation, that is, Galileo and BeiDou system, PPP further enhances and position accuracy is improved, particularly where higher number of satellites available and potential geometric strength of the GNSS constellation. This study investigates and evaluates the capability analysis of recently available multi GNSS dual frequency software package for static precise point positioning method using single system GPS, GLONASS, two system GPS/GLONASS, three system GPS/GLONASS/Galileo, GPS/GLONASS/BeiDou, and multi GNSS data observations. Seven days of datasets from seven IGS MGEX stations are adopted for the positioning solutions. The most obvious finding from this study is that PPPH software is well capable of estimating the position coordinate for the single, combined and multi GNSS PPP mode. PPP results for GPS, GLONASS and combined GPS/GLONASS are in-line with the previous studies (Martin et al., 2011; Choy et al., 2013; Abdullah et al., 2015). Though it also found that GLONASS PPP solutions have limited accuracy. There are some factors that influence the PPP estimates for GLONASS PPP. One of which may be GLONASS code pseudoranges IFBs. Inter-frequency bias parameters absorb the systematic part of code pseudoranges. 
PPP results reveal that combined GPS/GLONASS PPP solutions show better position quality compared with the GPS PPP solution. PPP solutions for GPS/GLONASS reach 4.10, 3.42 and $6.50 \mathrm{~cm}$ in east, north and up component, respectively. RMS 3D for GPS/GLONASS PPP solution is $8.96 \mathrm{~cm}$. RMS decrease by $2.0 \mathrm{~mm}$ and $15.0 \mathrm{~mm}$ compared with GPS alone PPP solutions in horizontal and 3D component, respectively. Difference of horizontal component between triple constellation and multi GNSS is only 1.0-2.0 mm. Latest contribution of Galileo system to the combined GPS/GLO/NASS PPP, which is accepted as under developed system (Tegedor et al., 2014). GPS/GLONASS/Galileo PPP solutions show a significant improvement of convergence time by $3.81 \%$ to achieve accuracy level of $3.0 \mathrm{~cm}$ over GPS/GLONASS/BeiDou PPP mode. Multi GNSS PPP show insignificant improvement of positioning accuracy in comparison with GPS/GLONASS/Galileo PPP solutions. The analysis results of static PPP show that 3D accuracy is improved for most stations when adding Galileo and BeiDou system to GPS/GLONASS PPP solutions. When PPP solutions from tripe constellation and multi GNSS are evaluated, it is found that the contribution of Galileo measurements is not uniform for all the IGS sites (Kiliszek et al., 2020). Multi-GNSS PPP reduce the convergence time by $11.69 \%$ and $2.26 \%$ over GPS/GLONASS/BeiDou and GPS/GLONASS/Galileo PPP results to converge $4.0 \mathrm{~cm}$. The analysis of results of IF phase and code residuals show that orbital type of the GPS code observations have $1.7 \mathrm{~cm}$ and $2.0 \mathrm{~m}$, respectively. Code residuals for Galileo system is significantly larger than $2.0 \mathrm{~m}$. BeiDou GEO satellite has smaller range of code residuals. It is also noticed that RMS of phase residuals for GLONASS and Galileo is 2.2 and $2.3 \mathrm{~cm}$. Phase residuals for BeiDou orbital type is different and reaches 1.0 and $1.6 \mathrm{~cm}$ for GEO and IGSO satellites, while RMS for MEO satellites is very large and about $1.8 \mathrm{~cm}$.

Most PPP solutions from the three combined PPP and multi GNSS solutions are not new as the study of references, but the integration of Galileo and BeiDou system with combined GPS/GLONASS results can provide a comprehensive idea of positioning accuracy and PPP limitations. Galileo and BeiDou still does not have corrections for the receiver antenna models, and the accuracy of the orbits/clocks of the satellites and other models are constantly being improved.

Acknowledgement. The author thanks the IGS Analysis and Data Center for providing GNSS data and products free of charge

\section{REFERENCES}

Abdallah. A., and Schwieger. V. (2016). "Static GNSS precise point positioning using free online services for Africa”. Survey Review. 48, 61-77. https://doi.org/10.1080/00396265.2015.1097595

Abd Rabbou. M. and El-Rabbany. A. (2015). "PPP Accuracy Enhancement Using GPS/GLONASS Observations in Kinematic Mode”, Positioning. 6 1-6, https://doi.org/10.4236/pos.2015.6100158.

Alkan. R., Ilçi. V., Ozulu. I., Saka. M. (2015). “A comparative study for accuracy assessment of PPP technique using GPS and GLONASS in urban areas". Measurement: Journal of International Measurement Confederation 1-8. https://doi.org/10.1016/j.measurement.2015.03.012

Bahadur. B., Nohutcu, M. (2019). “Comparative analysis of MGEX products for postprocessing multi-GNSS PPP”, $\quad$ Measurement. 145 361-369, https://doi.org/10.1016/j.measurement.2019.05.094. 
Bahadur. B., Nohutcu, M. (2018). "PPPH: a MATLAB-based software for multi-GNSS precise point positioning analysis”. GPS Solution. 22, 113. https://doi.org/10.1007/s10291-018-0777-z

Choy. S., Zhang. S., Lahaye, F., Héroux. P. (2013). “A comparison between GPS-only and combined GPS+GLONASS Precise Point Positioning”. Journal of Spatial Sciences. 58, 169190. https://doi.org/10.1080/14498596.2013.808164

Cai. C, and Y, Gao. (2007). "Precise point positioning using combined GPS and GLONASS observations", Journal of Global Positioning System. 6 (1) 13-22, https://doi.org/10.5081/jgps.6.1.13.

Cai. C, Y. Gao., L. Pan., J. Zhu. (2015). "Precise point positioning with quad constellations: GPS BeiDou, GLONASS and Galileo”, Advances in Space Research. 56 (1) 133-143, https://doi.org/10.1016/j.asr.2015.04.001.

Dawidowicz. K., Krzan. G. (2014). "Coordinate estimation accuracy of static precise point positioning using on-line PPP service, a case study”. Acta Geodynamica et Geophysica. 49, 3755. https://doi.org/10.1007/s40328-013-0038-0

Dong. Z., and S. Jin. (2018). "3-D water vapor tomography in Wuhan from GPS, BDS and GLONASS observations”. Remote Sensing. 10, 1-15. https://doi.org/10.3390/rs10010062

Guo. F, Li. X, Zhang. X, Wang. J. (2017). The contribution of Multi-GNSS Experiment (MGEX) to precise point positioning. Advances in Space Research. 59, 2714-2725. https://doi.org/10.1016/j.asr.2016.05.018

Guo. Q. (2015). "Precision comparison and analysis of four online free PPP services in static positioning and tropospheric delay estimation". GPS Solution. 19, 537-544. https://doi.org/10.1007/s10291-014-0413-5

Kouba. J. (2015). “A guide to using international GNSS service (IGS) products”, September 2015 update. http://kb.igs.org/hc/en-us/articles/ 201271873-A-Guide-to-Using-the-IGSProducts.

Kiliszek. D., and Kroszczynski. K. (2020). "Performance of the Precise Point Positioning method along with the development of GPS, GLONASS and Galileo systems"; Measurement.DOI:10.1016/j.measurement.2020.108009.

Li. R, Zheng. S, Wang. E, and Dai. L. (2020). Advances in BeiDou Navigation Satellite System (BDS) and satellite navigation augmentation technologies. Satellite Navigation. 1, 1-23. https://doi.org/10.1186/s43020-020-00010-2

Li. X, G. Dick, C. Lu, M. Ge, T. Nilsson, Ning, T., Wickert, J., Schuh, H., (2015a). "MultiGNSS Meteorology: Real-Time Retrieving of Atmospheric Water Vapor from BeiDou, Galileo, GLONASS, and GPS Observations”. IEEE Transactions of Geosciences and Remote Sensing. 53, 6385-6393. https://doi.org/10.1109/TGRS.2015.2438395

Li. X., Zhang. X., Ren. X. (2015b). "Precise positioning with current multi constellation Global Navigation Satellite Systems: GPS, GLONASS Galileo and BeiDou”, Scientific Reports. 5 8328, https://doi.org/10.1038/srep08328

Li. X, Ge. M, Dai. X, Ren, X, and Schuh. H. (2015c). Accuracy and reliability of multi-GNSS real-time precise positioning: GPS, GLONASS, BeiDou, and Galileo. Journal of Geodesy. 89, 607-635. https://doi.org/10.1007/s00190-015-0802-8

Liu. G, Zhang. X, Li. P. (2019). Improving the performance of Galileo uncombined precise point positioning ambiguity resolution using triple-frequency observations. Remote Sensing. 11. https://doi.org/10.3390/rs11030341 
Liu. T, Yuan. Y, Zhang B, Wang. N, Tan. B, Chen. Y. (2017). Multi-GNSS precise point positioning (MGPPP) using raw observations. Journal of Geodesy. 91, 253-268. https://doi.org/10.1007/s00190-016-0960-3

Lou. Y, Zheng. F, and Feng. Y. (2016). Multi-GNSS precise point positioning with raw singlefrequency and dual-frequency measurement models. GPS Solution. 20, 849-862. https://doi.org/10.1007/s10291-015-0495-8

Martín. A., Anquela. A., Capilla. R., Berné. J. (2011). "PPP technique analysis based on time convergence, repeatability, IGS products, different software processing, and GPS+GLONASS constellation". Journal of Surveying Engineering. 137, 99-108. https://doi.org/10.1061/(ASCE)SU.1943-5428.0000047

Malik. J.S. (2020). Performance analysis of Static precise point positioning using open-source gamp. Artificial Satellites. 55, 41-60. https://doi.org/10.2478/arsa-2020-0004

Malik. J.S., Jingrui. Z, Naqvi. N.A. (2018). Soil moisture content estimation using GNSS reflectometry (GNSS-R). 5th International Conference of Aerospace Science and Engineering. ICASE, Islamabad, Pakistan, pp. 1-9, 2017

Montenbruck. O., Steigenberger. P., Prange. L., and Deng. Z. et al. (2017). “The Multi-GNSS Experiment (MGEX) of the International GNSS Service (IGS) - Achievements, prospects and challenges. Adv. Sp. Res. 59, 1671-1697. https://doi.org/10.1016/j.asr.2017.01.011

Ogutcu. S. (2019). “Assessing the Contribution of Galileo to GPS+GLONASS PPP: Towards Full Operational Capability”, Measurement https://doi.org/10.1016/j.measurement.2019.107143

Pan. L, Zhang. X, Xingxing. Li, and Q. Wang. (2019). "Satellite availability and point positioning accuracy evaluation on a global scale for integration of GPS, GLONASS, BeiDou and Galileo. Adv. Sp. Res. 63, 2696-2710. https://doi.org/10.1016/j.asr.2017.07.029

Pan. Z, Chai. H, Kong. Y. (2017). "Integrating multi-GNSS to improve the performance of precise point positioning. Adv. Sp. Res. 60, 2596-2606. https://doi.org/10.1016/j.asr.2017.01.014

Su. K., Jin. K., Jiao. G. (2020). “Assessment of multi-frequency GNSS PPP models using GPS, Beidou, GLONASS, Galileo and QZSS”, Measurement Science and Technology. https://doi.org/10.1088/1361-6501/ab69d5

Tegedor. J, Øvstedal. O, Vigen. E. (2014). Precise orbit determination and point positioning using GPS, Glonass, Galileo and BeiDou. Journal of Geodetic Sciences. 4, 65-73. https://doi.org/10.2478/jogs-2014-0008

Wanninger. L. (2012). "Carrier-phase inter-frequency biases of GLONASS receivers. Journal of Geodesy. 86, 139-148. https://doi.org/10.1007/s00190-011-0502-y

Xia. F, Ye. S, Xia. P, and Hu. G. (2019). Assessing the latest performance of Galileo-only PPP and the contribution of Galileo to Multi-GNSS PPP. Advances in Space Research. 63, 27842795. https://doi.org/10.1016/j.asr.2018.06.008

Yigit, C.O., Gikas, V., Alcay, S., Ceylan, A. (2014). "Performance evaluation of short to long term GPS, GLONASS and GPS/GLONASS postprocessed PPP. Survey Review. 46, 155-166. https://doi.org/10.1179/1752270613Y.0000000068

Zhao. Q, Wang. C, Guo. J, Liu. X. (2015). “Assessment of the contribution of BeiDou GEO, IGSO, and MEO satellites to PPP in Asia-Pacific region. Sensors 15, 29970-29983. https://doi.org/10.3390/s151229780 
Zumberge, J.F., Heftin, M.B., Jefferson, D.C., Watkins, M.M. (1997). Precise point ositioning for the efficient and robust analysis of GPS data from large networks. J. Geophys. Res. 102, 5005-5017.

Received: 2020-07-22

Reviewed: 2020-08-27 (G. Krzan), 2020-09-24 (undisclosed name)

Accepted: 2020-12-08 